
\title{
Research S Surate \\ Time Evolution of Tectonic Earthquake in Ambon, Indonesia
}

\section{Made Kris Adi Astra ( $\square$ made.adiastra@gmail.com )}

Geophysical Institute (GPI), Karlsruhe Institute of Technology

Andreas Rietbrock

Geophysical Institute (GPI), Karlsruhe Institute of Technology

Nasim Karam Zadeh Toularoud

Geophysical Institute (GPI), Karlsruhe Institute of Technology

\section{Research Article}

Keywords: earthquake seismology, earthquake detection, Ambon earthquake, virtual stress-meter analysis

Posted Date: February 23rd, 2021

DOl: https://doi.org/10.21203/rs.3.rs-236186/v1

License: (1) This work is licensed under a Creative Commons Attribution 4.0 International License.

Read Full License 


\title{
Time Evolution of Tectonic Earthquake in
}

\section{Ambon, Indonesia}

\author{
I Made Kris Adi Astra $^{1 *, 2}$, Andreas Rietbrock ${ }^{1}$, Nasim Karam Zadeh Toularoud ${ }^{1}$ \\ ${ }^{1}$ Geophysical Institute (GPI), Karlsruhe Institute of Technology, Germany \\ ${ }^{2}$ Meteorology Climatology and Geophysics Agency, Indonesia
}

\begin{abstract}
The advancement of earthquake seismology brings a new insight into earthquake detection. Advanced signal processing by implementing sliding-window mathematical techniques of crosscorrelation into data stream are able to recognize low amplitude earthquake signals even under the presence of noise. Clear detection of the onset of low amplitude seismic waves is crucial, however they often hidden by larger amplitudes of coda waves after the generation of mainshock event.
\end{abstract}

By performing template matching algorithm we found a detail temporal variation of seismicity related to Mw 6.6 Ambon earthquake. In comparison, the detection level is up to eight times from conventional method. The method also reveals a seismic migration before the main event coincide with the direction of local tectonic movement derived from previous GPS analysis. Since the method able to detect the earthquake within their family, it gives a reasonably significant improvement to virtual stress-meter analysis. Highly accumulated stress preceding the main event depicted by $b$-value drop are clearly mapped in a high confidence level.

\section{Introduction}

Destructive Mw 6.6 crustal earthquake hit the Ambon region in the eastern part of Indonesia on 25 September 2019 at 23:46:44.543 UTC. As reported by BMKG, the earthquake hypocentre was located at $10 \mathrm{~km}$ depth. The mainshock was then followed by numerous aftershock events and caused extensive damage to inhabitant facilities. Mechanism of the mainshock and two following aftershocks larger than $\mathrm{Mw} 5$ were strike-slip faultings according to the BMKG catalog. The main event has: NP1 Strike: 165.7, Dip: 80.5, Rake: 179.8; NP2 Strike: 255.73, Dip: 89.8, Rake: 9.5 [1]. 
Seismicity distributions in the Ambon region are mainly generated by the complex area of Banda subduction (BS), Seram Megathrust (SM), Kawa fault (KF), Banda detachment (BD), South Seram thrust (SST), volcanic arc (VA) and numerous local faults (LF). Banda subduction and Seram megathrust bend $180^{\circ}$ in a curvy shape (figure 1). The complexity of the tectonic regime in the subduction zone is represented by the inner volcanic arc [2]. The subduction zone generates earthquakes from shallow hypocentral depth to deep-focus earthquakes reaching $499 \mathrm{~km}$. Although debate on how the morphology of the Banda-Seram subduction system was formed by the single slab or two subduction zone is still on going, tomographic images and investigation on earthquake hypocentre show that the slab ends at $660 \mathrm{~km}$ in mantle discontinuity [3] [4] [5]. Remarkable inland Kawa fault shows left-lateral faulting style in the island of Seram. Trending ESE-WSW and in line with the Kawa river [6]. The fault indicates a connection with the low angle down-dip fault of the Banda detachment [7] [8], while the eastern part of the Kawa fault and exposed Banda detachment meets at Taluti bay.

Mw 6.6 earthquake on 25 of September 2019 located in the Seram strait in the north-eastern direction of Ambon island. Surrounded by one of the most active tectonic triple junctions in the world, there were few seismicity reported in the epicenter area of the $2019 \mathrm{Mw} 6.6$ earthquake according to the historical earthquake catalog of BMKG and United States Geological Survey [9]. Harvard GCMT comprises only one historical event on August $17^{\text {th }}, 1980$, Mw 5.3 [10] [11]. In contrast, there are at least seven large earthquakes of magnitude 6.6 to 7.3 recorded between 1919 to 2015. They occurred in a radius of $\sim 1^{0}$ from the Seram strait. Those shallow crustal events are associated with the activity of South Seram Thrust, Seram Subduction, and local faults. A large destructive tsunami in the Ambon region is written in history. It occurred in 1674 and caused 2300 fatalities. Extreme tsunami run-up reaches $100 \mathrm{~m}$. A recent study by Pranantyo and Cummins [8] elaborates that two candidate faults are likely to generate the earthquake-triggering tsunami, the South Seram Thrust and shallow crustal fault on Ambon. The unnamed Ambon fault where the 2019 Ambon earthquake occurred had less attention from seismologists because of its quietness. It lies beneath the narrow Ambon Strait and seafloor bathymetric are of poor quality and makes it hard to identify fault systems. It pushes our curiosity to investigate the detailed temporal evolution of seismicity in the long-known inactive area of Seram Strait, Ambon region. 

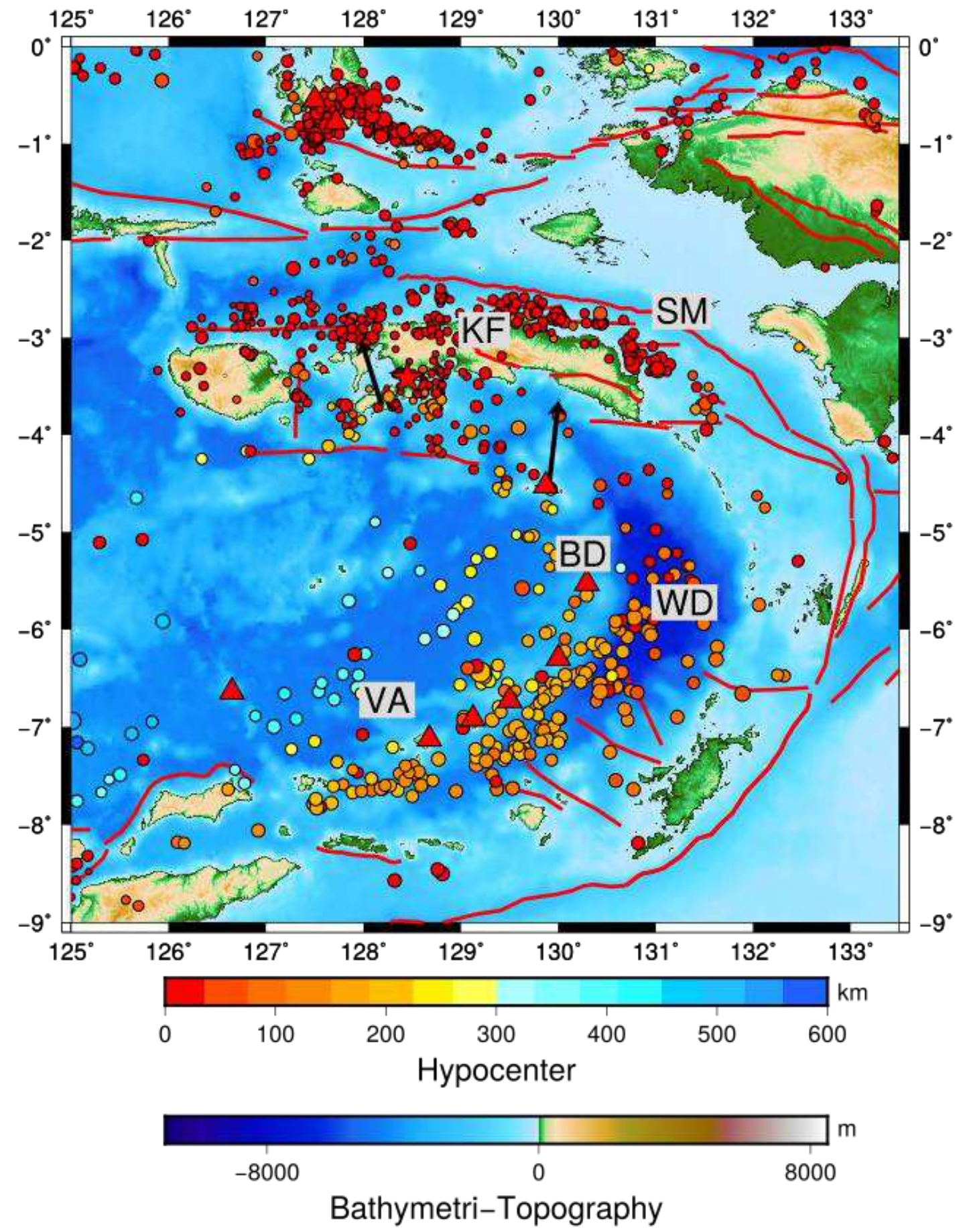

Figure 1. Tectonic context of Ambon-Seram-Banda region. Circles are seismicity, and triangles indicate the active volcano. The red star is mainshock of Mw 6.6 in 2019. Red lines show fault lines of geological features. Black arrows are horizontal crustal velocity vector, adapted from Koulali et al [12]. Earthquakes are shown between the 1st of January 2019 to 25 September 2019. 


\section{Foreshock, Mainshock and aftershock temporal activities}

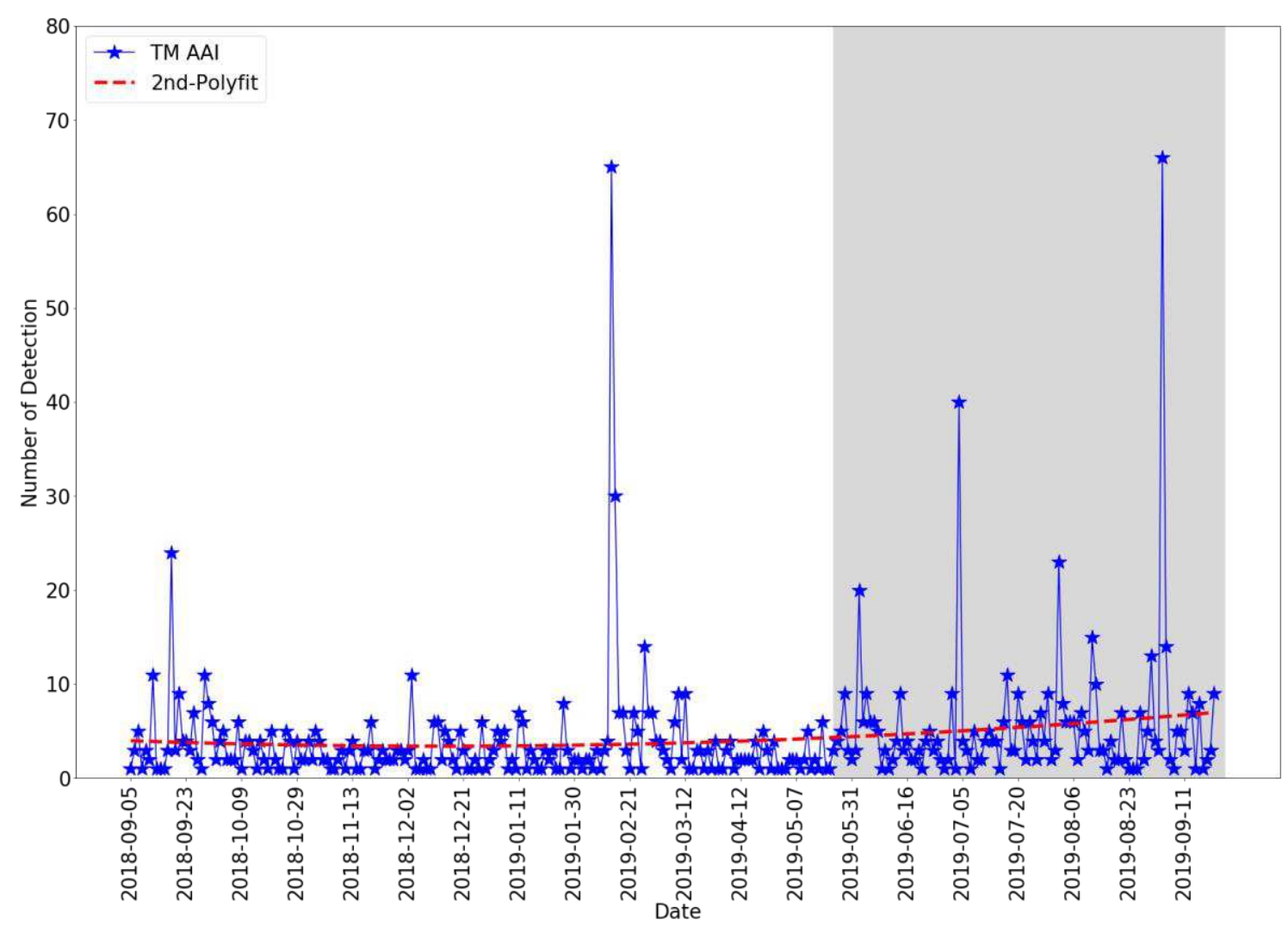

Figure 2. Background seismicity time-evolution. Grey shaded figure shows seismicity-rate increment before the mainshock.

We perform template matching technique to detect earthquake signal by assigning well relocated 237 template events from the work of Sahara et.al., [13] to continuous signal from five seismic stations around the epicenter owned by Indonesian Meteorology Climatology and Geophysics Agency (BMKG). Scanning from the early of September 2018, we found seismicity patterns before the mainshock of the Ambon earthquake. The level of background seismicity from early of September 2018 until next ten months were 3.73 events per day on their average value. A gradual increasing rate of preceding events started four months before the mainshock. The time interval between each detected event became longer. Furthermore, progressive increasing rate of background seismicity almost twice as large from previous seismicity rate of 6.28 events per day began since $2^{\text {nd }}$ of July 2019 as depicted in figure 2 . We believe that this phenomenon was related to the crack-opening prior to the sudden energy release of the mainshock. Increment background seismicity follows the second-order regression-polynomial fitting. There was no significant growth of seismicity in several hours before the mainshock. During the day of mainshock occurrence, AAI is the nearest station on the very active cluster. A sharp increase in seismicity was observed from 25 September to 26 September 2019. 
Utilizing Frequency-Magnitude Distribution technique of $b$-value which act as stressmeter have been reported to assessed tectonic seismicity. In a good agreement between the laboratory experiment and local-seismicity of Parkfield, Schorlemmer and Wiemer [14] [15] found that the future earthquake rupture initiated in the low $b$-value region where indicates highly stressed area. Works of Scholz [16] demonstrated that $b$-value linearly drop while differential stress were applied. Investigation of gradual unlocking preceding the M 8.1 Iquique earthquake on 1 April 2014 indicated that $b$-value decreased since 2000 days before the main event, down to 0.5 [17].

We observed two stages of $b$-value temporal variation in relation to the seismicity rate. First, in a year observation before the mainshock $b$-value drop drastically to 0.4 from July to the end of August 2019 (figure 3-lower). The phenomenon indicated a long stress accumulation increased before the rupture started. Among this period earthquake size distribution declined. Interval between mean magnitude and minimum magnitude in the time window became larger. In contrast to the longstanding stress built-up in the first stage, a short increment of earthquake size distribution was observed in the early of September 2019 and identified as the second stage of $b$-value variability. The rebound is a consequence from numerical calculation of short interval between minimum magnitude and mean magnitude on their specific time window before mainshock (figure

\section{3-upper).}

At the selected time span six weeks before the main event from 14 August 2019 to one hour+ after the mainshock the rate of seismicity increased (figure 4). The seismicity distribution clearly indicated a planar structure that we interpret as the fault line dividing two blocks of Earth's crust. The main cluster of seismicity migrated following the fault strike. Another cluster of seismicity located on the right side of the fault edge or geographically in the north-eastern part and might indicate rock collision between the edge of fault block and adjacent geological structure.

Spatial variation of the earthquakes temporal change occurrence tended to increase at the eastern block of the fault, primarily in the northernmost of the fault edge. Since then, we suggest that the eastern block is the primary fault which moved relatively to the other block. We found a relationship of the spatio-temporal earthquake rupture propagation to a certain direction was controlled by the tectonic stress regime in the region. An investigation of crustal strain partitioning based on GPS observation informed that crustal motion velocities vector leads to the direction of NNE in the Banda Neira Island then continue to rotate to NNW in the Ambon Island [12](figure 1.), in the same direction with the focal mechanism strike. The general agreement was consistent until one hour after the mainshock. 

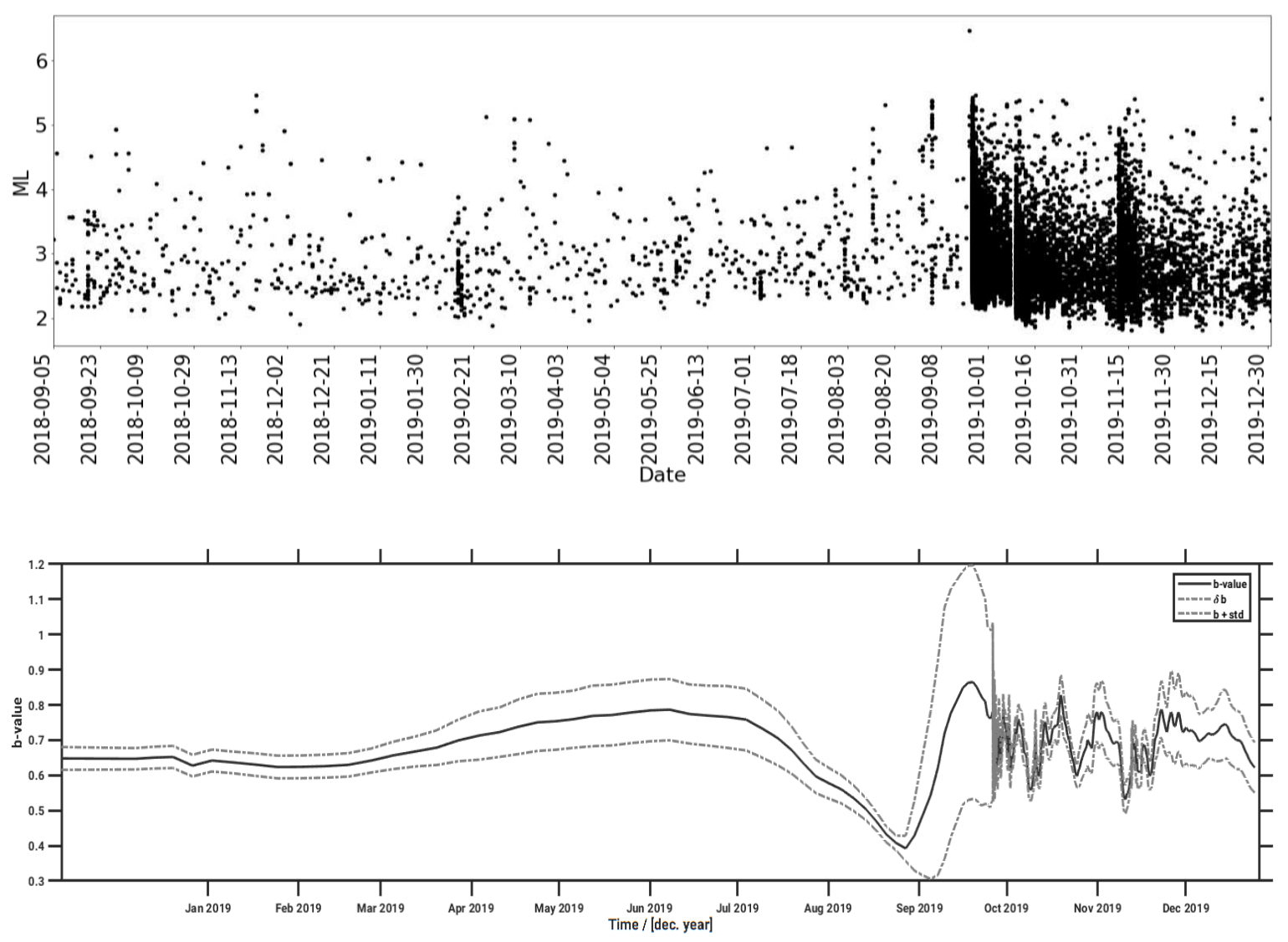

Figure 3. Magnitude plot over time (upper). Temporal $b$-value which act as stressmeter indicating stress accumulation observed one year before the mainshock. The value drop reaching 0.4 in the end of August 2019 (lower).

Two large aftershocks were detected by template matching algorithm. At two nearest station of AAI and KRAI, the seismic evolution are mapped properly (figure 5). The second large aftershock of Mw 5.1 coincided with a sharp increment of seismic activity 47 days after the mainshock. In number, 986 aftershock events were detected. The event interval were roughly every 20 seconds (figure 6). We suggest that the series of the seismicity did not randomly distributed nor independent; it represents interaction of earthquake triggering after the mainshock event. Prior to the mainshock, seismicity tended to be aseismic, despite in a short term of nucleation process before the main event. Then, we consider the aftershock distribution is mainly caused by the aseismic afterslip. 

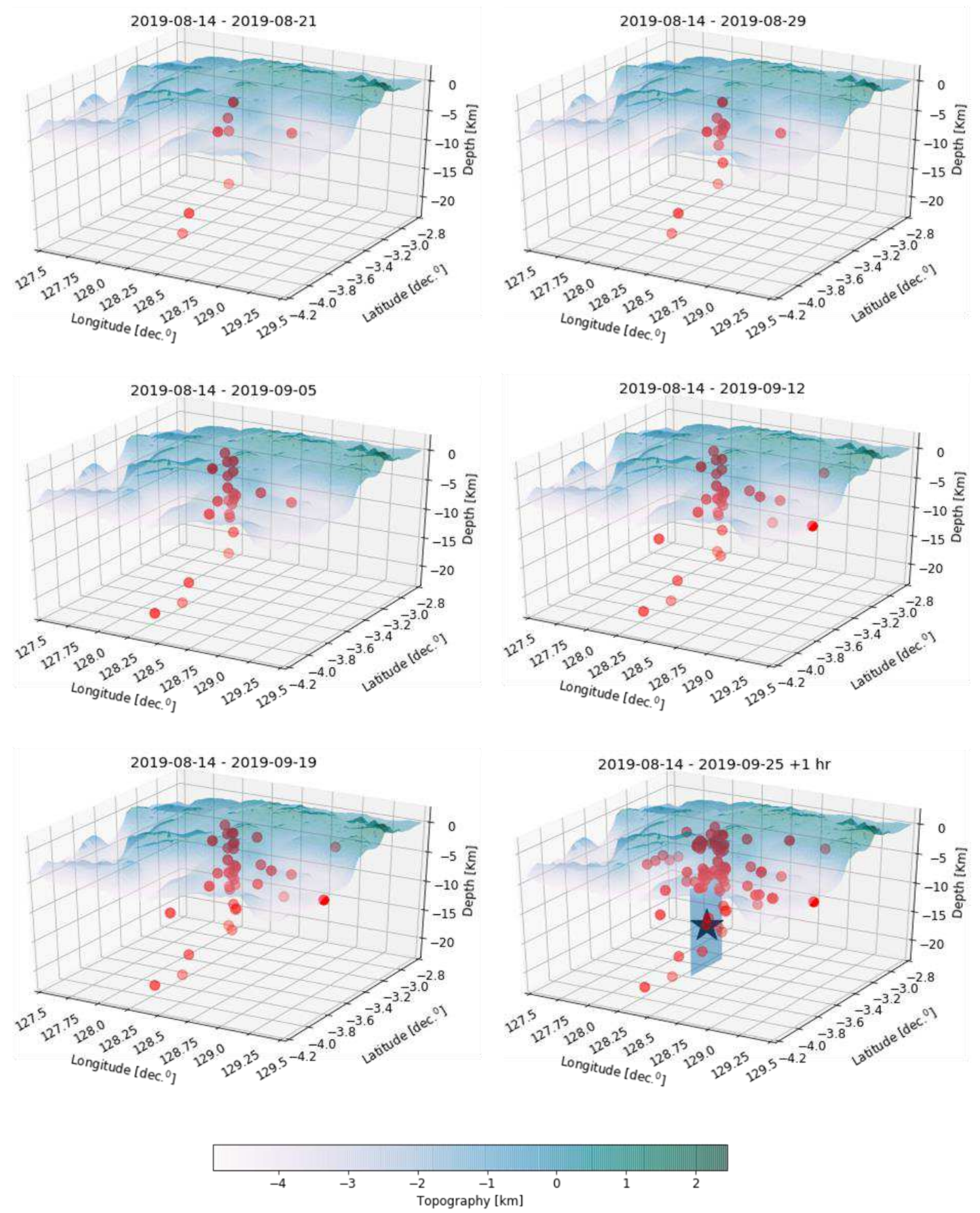

Figure 4. Seismicity growth episode preceding the Mw 6.6 Ambon earthquake at a selected timeline. The black star depicts the mainshock, red dot indicating seismicity. Blue patches showing fault area estimation, please note that the differences of scaling in longitude-latitude in decimal degree and depth in $\mathrm{km}$. 


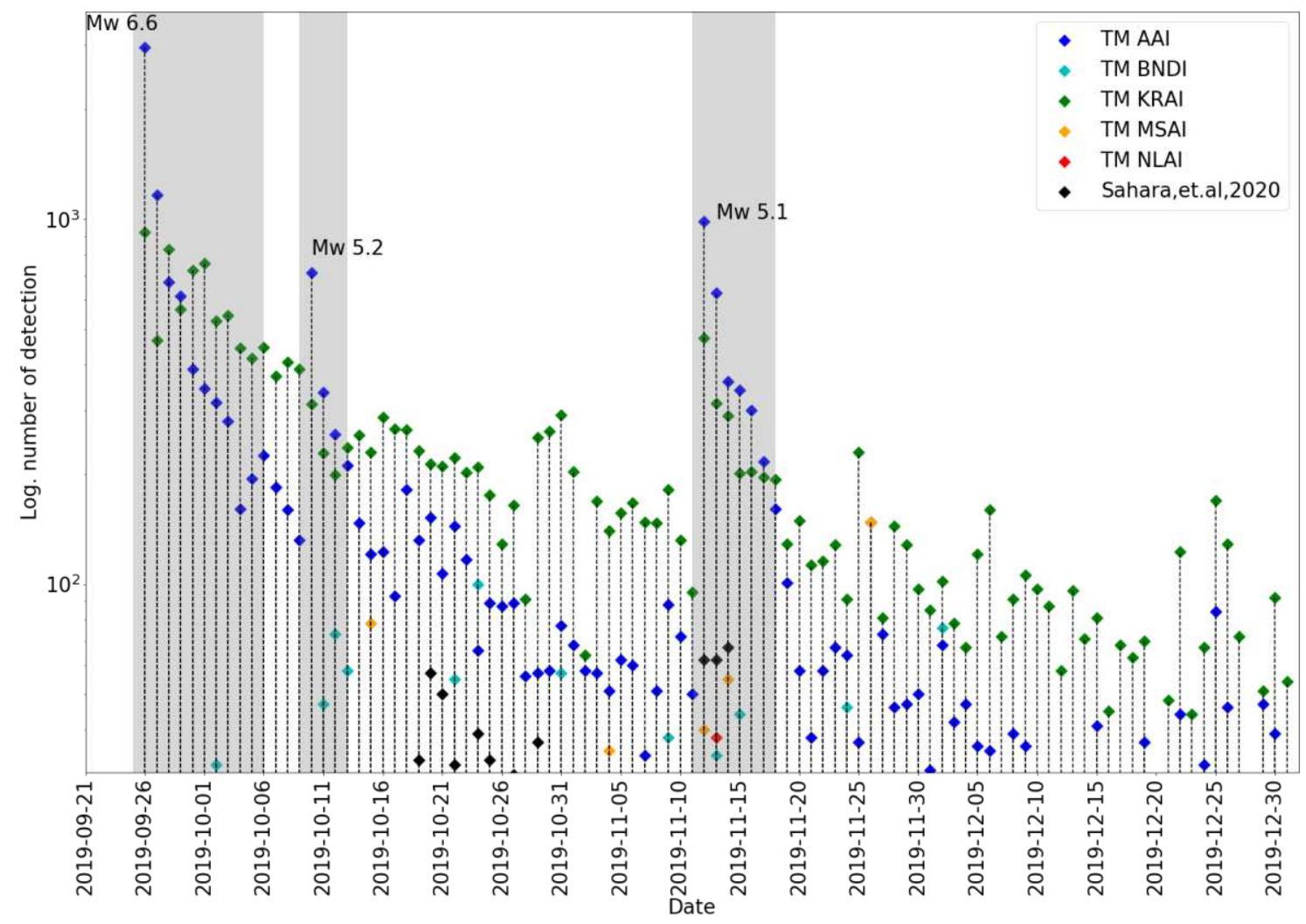

Figure 5. Detection of template matching at each station around the epicentre of Mw 6.6 Ambon earthquake.

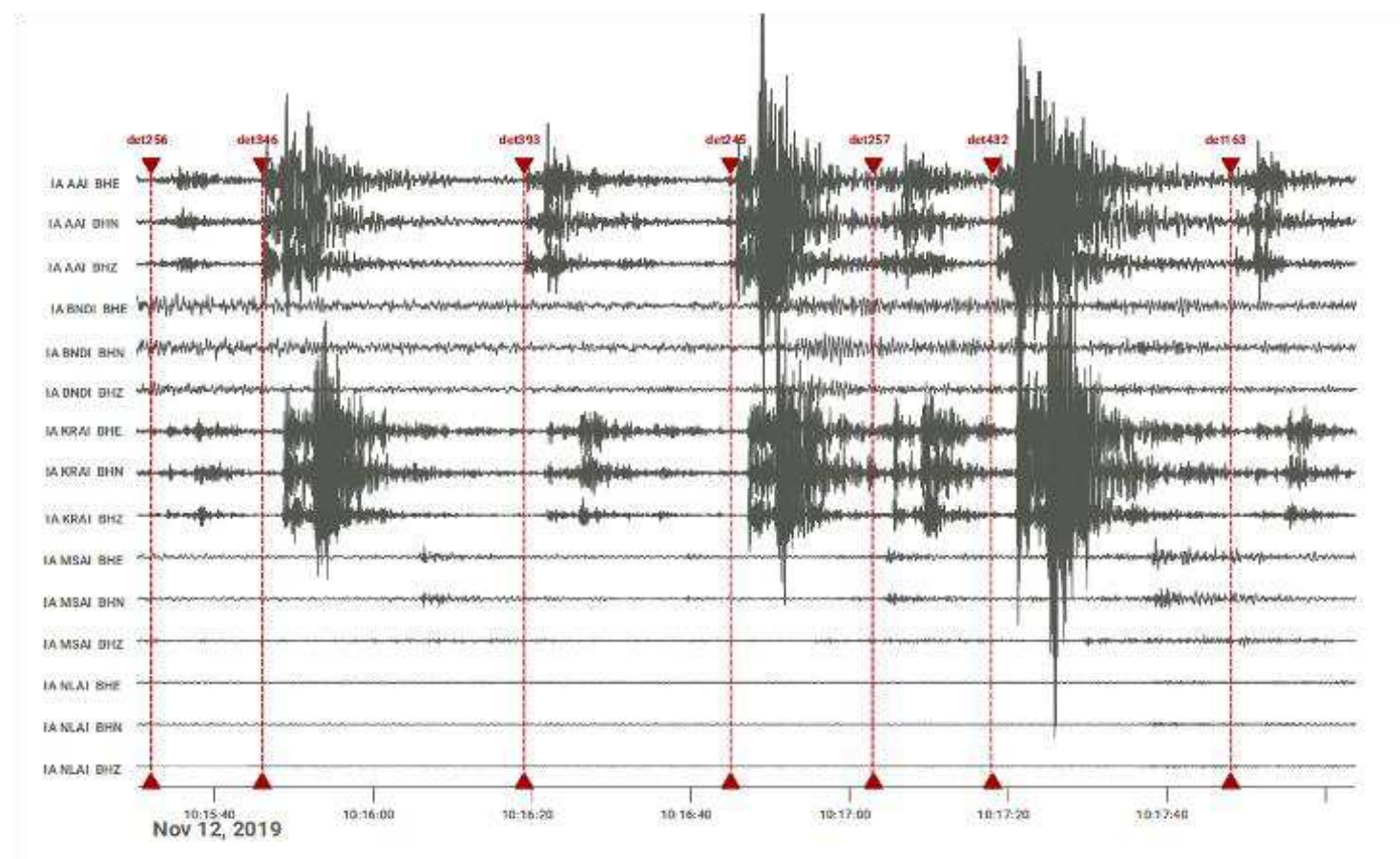

Figure 6. Earthquake sequence on 12 November 2019. Red lines indicate detection time performed by the template matching algorithm. 


\section{Conclusion}

In comparison, template matching detected almost eight times more events than conventional seismology method. It gives an novel insight of how dense an earthquake series following a large magnitude event is generated until several days afterward. Larger amplitude of coda waves coveredup the low-amplitude events, overlapping arrival time of two or more earthquakes and low quality of onset signature clarity were challenging issues of conventional earthquake detection. They are not observable by the seismologist on duty nor un-locatable due to single instrument detection. Even though in our template matching detection, numerous detected events are only detected by the closest station of AAI. Associating the travel time from the earthquake location, we got 783 pairs of events recorded by all five stations.

Since the method improves the number of earthquakes in the catalog significantly within their family events, it provides advantages to the further seismological analysis. Individual time evolution of stress loading that only caused by the specific tectonic activities successfully mapped. A bias and inconsistent result eventually found in stress-meter analysis while using standard catalog event without template matching technique. It mainly come from earthquake catalog selection which only consider a spatial context and potentially contains several different earthquake clusters with distinctive stress loading pattern. Furthermore, detailed migration of low-amplitude event seismicity preceding the main event were identified.

\section{Method}

\section{Template matching earthquake detection}

Template matching algorithm is used to detect earthquake waveforms from five continuous seismic signal of IA broadband network owned by Indonesian Meteorology, Climatology and Geophysics Agency. The method is robust to detect earthquake waveform even in a presence of noises. Since then, low amplitude event which may cover-up by large amplitude of coda waves is able to detect. This finding provides a significant improvement of earthquake physics.

Template waveform is obtained from 1151 aftershock events from 2019-10-19 to 2019-12-14 after Mw 6.6 Ambon earthquake on 25 September 2019. The magnitude range between Mw 1.91 to $\mathrm{Mw}$ 5.15. Eleven temporary broadband stations of ITB and four permanent station broadband 
seismographs of BMKG were used [13]. Template waveform and continuous waveform were threated with the same sampling rate of $20 \mathrm{~Hz}$. We apply a bandpass filter between $1.0 \mathrm{~Hz}$ and 8.0 $\mathrm{Hz}$, just slightly below the Nyquist frequency of the data.

Anticipating template redundancy by means of the template are well correlate among each other, we performed a two-step de-clustering strategy to reduce the number of template events. First, by using the event template above Mw 3. It has been done by an assumption that lower magnitude events are scalable in logarithmic terms with the magnitude above our threshold. In comparison to the original catalog of template events, selected event templates represent adequate spatial distribution. Second, by performing waveform clustering based on their cross-correlation value above 0.55 . As final template, we got 237 high quality template waveforms. We deploy match-filter detection [18] and assign 14 times of median absolute deviation of cross-correlation sum as detection threshold.

To assess the seismicity distribution of earthquake size we perform frequency-magnitude distribution as formulated by Gutenberg and Richter [19] as: $\log N=a-b M$, where $N$ describe the number of earthquake larger than magnitude of $M$ in the catalog. The size of earthquake were calculated by local magnitude formulation [20]; [21]. The earthquake size distribution is expressed by the gradient of $b$, while $a$ express the earthquake productivity [22]. Maximum-likelihood method is used to determine $b$-values which could be expressed through the following equation:

$$
b=\frac{1}{\bar{M}-M_{\min }} \log e
$$

where $\bar{M}$ is the mean of magnitude, $M_{\min }$ denotes the minimum magnitude in the catalog [14]. Furthermore, the confidence limit of the b-value is described by standard deviation [23]; [15] using the equation of:

$$
\delta b=2.30 b^{2} \sqrt{\sum_{i=1}^{n} \frac{\left(M_{i}-\bar{M}\right)^{2}}{n(n-1)}}
$$

$n$ represent the total number of events. $b$-value are calculated above the magnitude of completeness $(M c)$. Temporal $b$-value calculation was carried out in the ZMAP seismicity analysis package [24]. Examining the spatial distribution of the Ambon earthquake series, we conduct absolute earthquake localization analysis. The continuous waveform data were associated with the detection time from matching filter detection. We used SDX-Seismic Data Explorer [25]; [26] to assign a minimum of three P-phase onsets, or combination of three P- and S- from our stations. A very local crustal seismic velocity model of the Ambon region [13] is used. 
Signal pre-processing were done in ObsPy package [27], map were produced using GMT [28] and seismogram viewer in figure 6 produced using Snuffler [29].

\section{References}

BMKG. BMKG-Earthquake Repository. http://repogempa.bmkg.go.id/

Sandiford, M. Complex subduction. Nature Geoscience vol. 3 518-520 (2010).

Spakman, W. \& Hall, R. Surface deformation and slab-mantle interaction during Banda arc subduction rollback. Nature Geoscience vol. 3 562-566 (2010).

Das, S. Seismicity gaps and the shape of the seismic zone in the Banda Sea region from relocated hypocenters. Journal of Geophysical Research vol. 109 (2004).

Pownall, J. M., Hall, R. \& Watkinson, I. M. Extreme extension across Seram and Ambon, eastern Indonesia: evidence for Banda slab rollback. Solid Earth vol. 4 277-314 (2013).

Watkinson, I. M. \& Hall, R. Fault systems of the eastern Indonesian triple junction: evaluation of Quaternary activity and implications for seismic hazards. Geological Society, London, Special Publications vol. 441 71-120 (2017).

Pownall, J. M., Hall, R. \& Lister, G. S. Rolling open Earth's deepest forearc basin. Geology vol. 44 947-950 (2016).

Pranantyo, I. R. \& Cummins, P. R. The 1674 Ambon Tsunami: Extreme Run-Up Caused by an Earthquake-Triggered Landslide. Pure and Applied Geophysics vol. 177 1639-1657 (2020).

USGS. Significant Earthquakes. https://earthquake.usgs.gov/earthquakes/browse/significant.php

Dziewonski, A. M., Chou, T.-A. \& Woodhouse, J. H. Determination of earthquake source parameters from waveform data for studies of global and regional seismicity. Journal of Geophysical Research: Solid Earth vol. 86 2825-2852 (1981).

Ekström, G., Nettles, M. \& Dziewonski, A. M. The Global CMT project 2014-2010: Centroidmoment tensors for 13,017 earthquakes. Phys. Earth Planet. Inter. 200-201, 1-9 (2012). 
Koulali, A. et al. Crustal strain partitioning and the associated earthquake hazard in the eastern Sunda-Banda Arc. Geophysical Research Letters vol. 43 1943-1949 (2016).

Sahara, D. P. et al. Source mechanism and triggered large aftershocks of the Mw 6.5 Ambon, Indonesia earthquake. Tectonophysics vol. 799228709 (2021).

Schorlemmer, D. \& Wiemer, S. Earthquake Statistic at Parkfield: 1. Stationary of b values. J. Geophys. Res. 109, (2004).

Schorlemmer, D. \& Wiemer, S. Using b-value as Stressmeter to forecast future rupture areas. In vol. 2004 S51C-0170Z (2004).

Scholz, C. H. On the stress dependence of the earthquake b value. Geophysical Research Letters vol. 42 1399-1402 (2015).

Schurr, B. et al. Gradual unlocking of plate boundary controlled initiation of the 2014 Iquique earthquake. Nature 512, 299-302 (2014).

Chamberlain, C. J. et al. EQcorrscan: Repeating and Near-Repeating Earthquake Detection and Analysis in Python. Seismological Research Letters vol. 89 173-181 (2018).

Gutenberg, B. \& Richter, C. F. Frequency of earthquakes in California. Bull. Seismol. Soc. Am. (1944).

Bormann, P. \& Wendt, S. Seismic sources and source parameters. -in: Bormann, P. (Ed.), New Manual of Seismological Observatory Practice 2 (NMSOP2). Potsdam, Deutsches GeoForschungsZentrum GFZ. 1-259 (2013).

IASPEI. Summary of Magnitude Working Group recommendations on standard procedures fordetermining earthquake magnitudes from digital data, preliminary version October 2005. (2005)

El-Isa, Z. H. \& Eaton, D. W. Spatiotemporal variations in the b-value of earthquake magnitudefrequency distributions: Classification and causes. Tectonophysics vols 615-616 1-11 (2014).

Shi, Y. \& Bolt, B. A. The standard error of the magnitude-frequency b value. Bull. Seismol. Soc. Am. 72, 1677-1687 (1982)

Wiemer, S. A Software Package to Analyze Seismicity: ZMAP. Seismological Research Letters vol. 72 373-382 (2001). 
Rietbrock, A. \& Scherbaum, F. The GIANT Analysis System (Graphical Interactive Aftershock Network Toolbox). Seismological Research Letters vol. 69 40-45 (1998).

Heath, A. SDX (Seismic Data Explorer). (2010).

Beyreuther, M. et al. ObsPy: A Python Toolbox for Seismology. Seismological Research Letters vol. $81530-533$ (2010).

Wessel, P., Smith, W. H. F., Scharroo, R., Luis, J. \& Wobbe, F. Generic Mapping Tools: Improved Version Released. Eos, Transactions American Geophysical Union vol. 94 409-410 (2013).

Heimann, S. et al. Pyrocko - An open-source seismology toolbox and library. (2017) doi:10.5880/GFZ.2.1.2017.001 


\section{Acknowledgement}

The research is funded by LPDP

\section{Author information}

\section{Affiliations}

Geophysical Institute (GPI), Karlsruhe Institute of Technology, Hertzstrasse 16, Geb. 6.42, 76187, Karlsruhe, Germany

I Made Kris Adi Astra, Andreas Rietbrock, Nasim Karam Zadeh Toularoud

Meteorology Climatology and Geophysics Agency (BMKG), Jl. Pulau Tarakan No. 1, 80113, Denpasar, Bali, Indonesia

I Made Kris Adi Astra

\section{Contributions}

IMKAA run the template matching and wrote the manuscript, AR contributed to idea set-up, provided review, comment and suggestions, NKZT contributed to reviewing technical aspect of the template matching algorithm.

\section{Ethics declarations}

\section{Competing interests}

The authors declare no competing financial interests. 


\section{Figures}
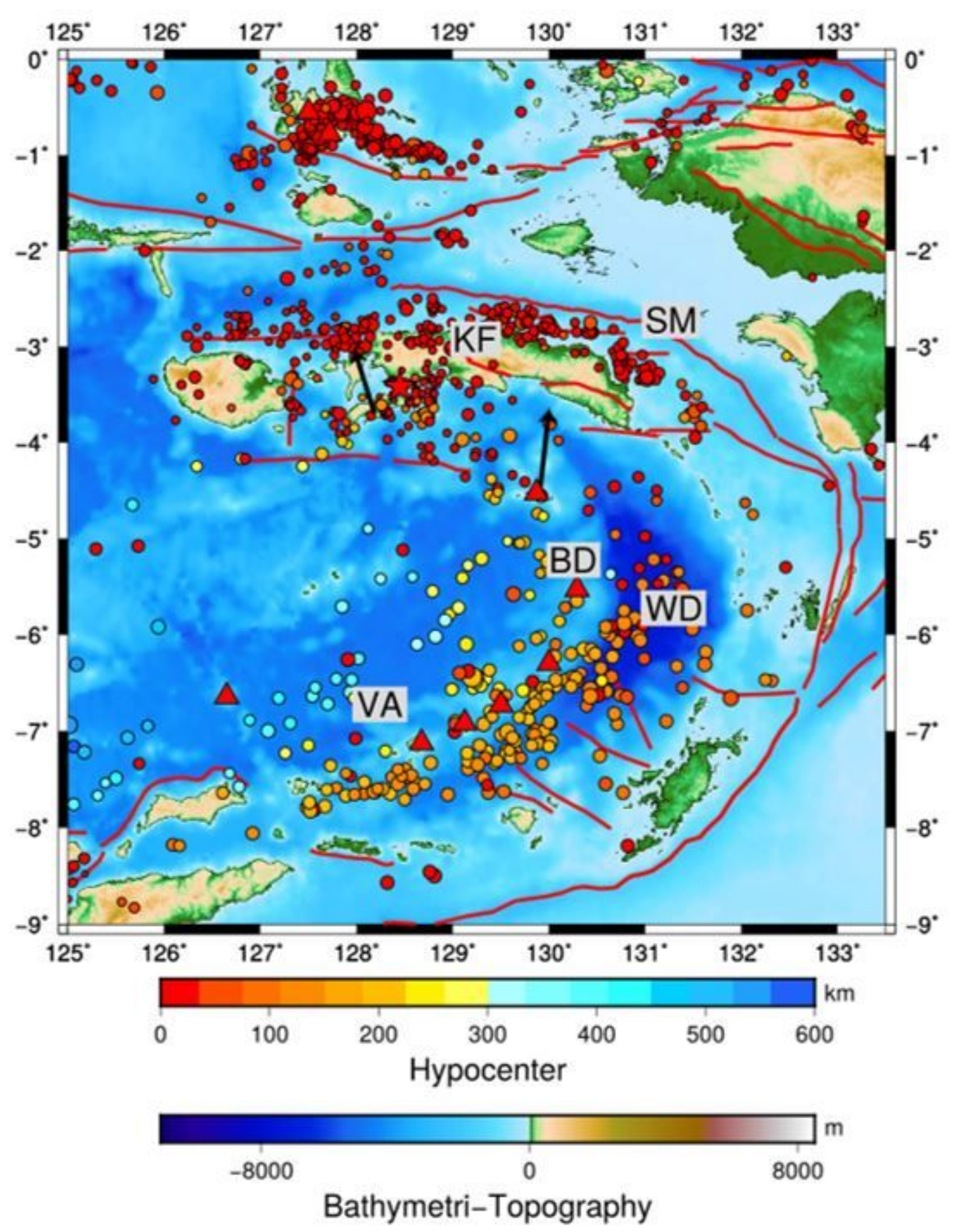

\section{Figure 1}

Tectonic context of Ambon-Seram-Banda region. Circles are seismicity, and triangles indicate the active volcano. The red star is mainshock of Mw 6.6 in 2019. Red lines show fault lines of geological features. Black arrows are horizontal crustal velocity vector, adapted from Koulali et al [12]. Earthquakes are shown between the 1 st of January 2019 to 25 September 2019. Note: The designations employed and the presentation of the material on this map do not imply the expression of any opinion whatsoever on the 
part of Research Square concerning the legal status of any country, territory, city or area or of its authorities, or concerning the delimitation of its frontiers or boundaries. This map has been provided by the authors.

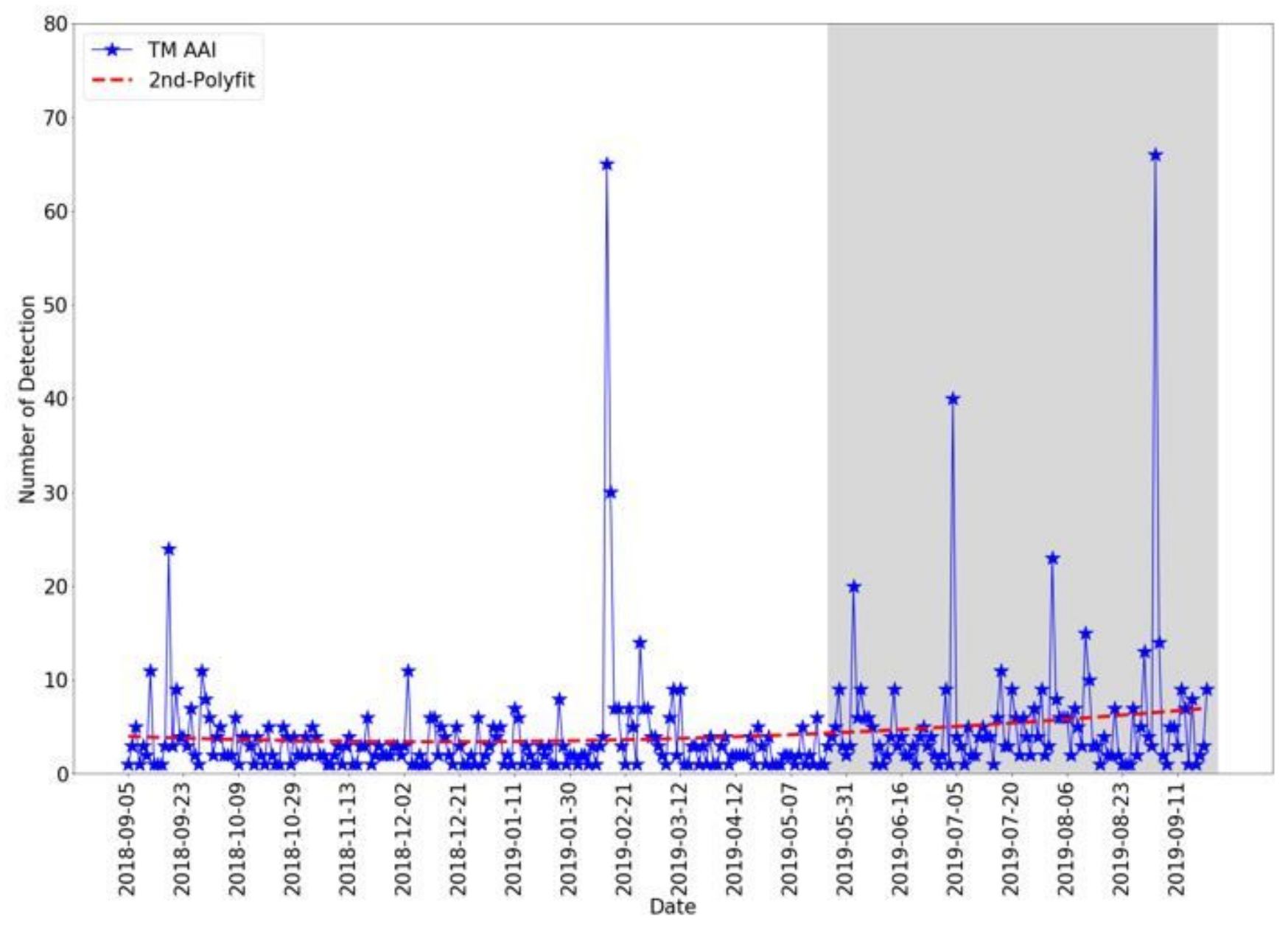

\section{Figure 2}

Background seismicity time-evolution. Grey shaded figure shows seismicity-rate increment before the mainshock. 

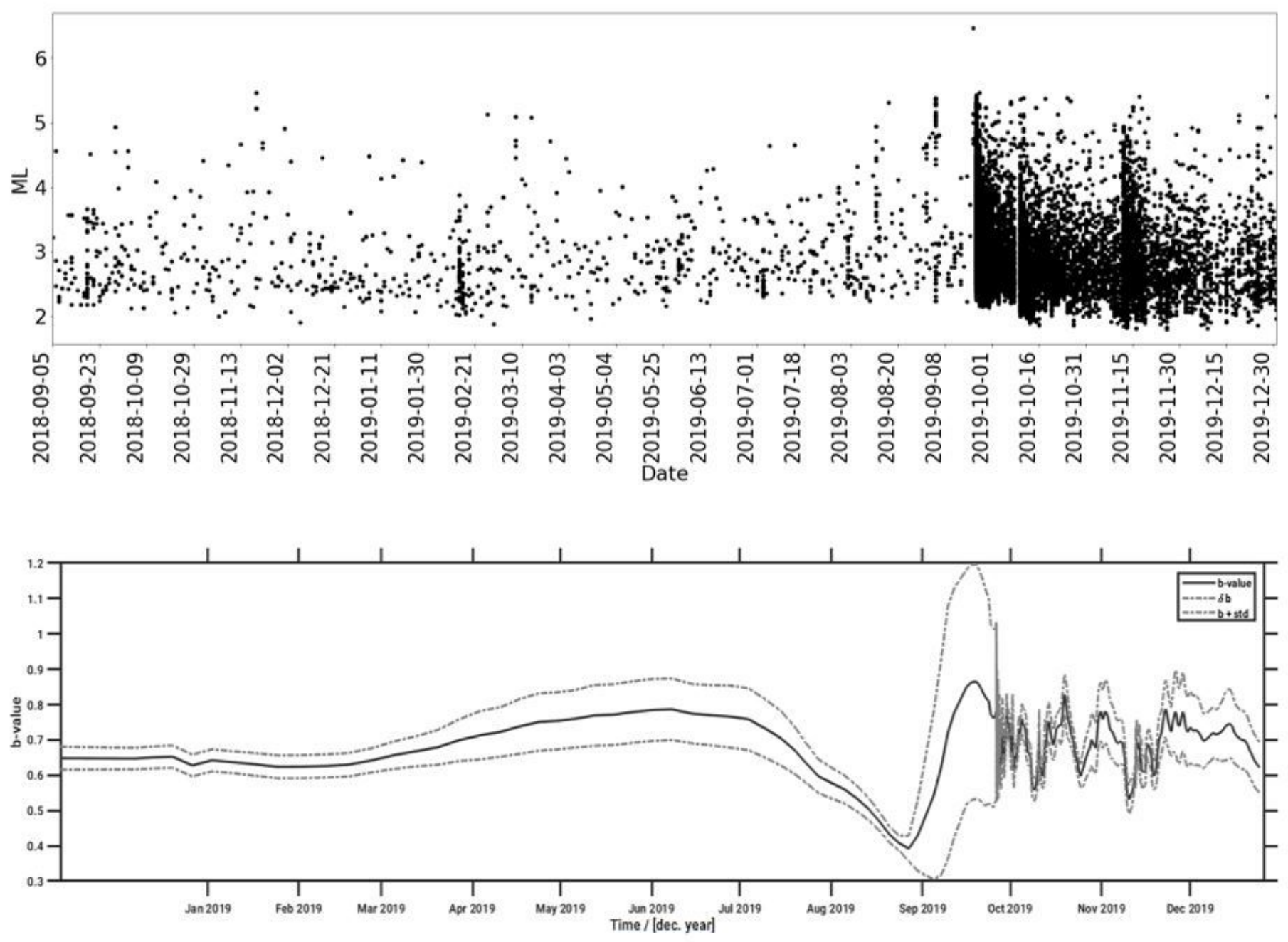

Figure 3

Magnitude plot over time (upper). Temporal b-value which act as stressmeter indicating stress accumulation observed one year before the mainshock. The value drop reaching 0.4 in the end of August 2019 (lower). 

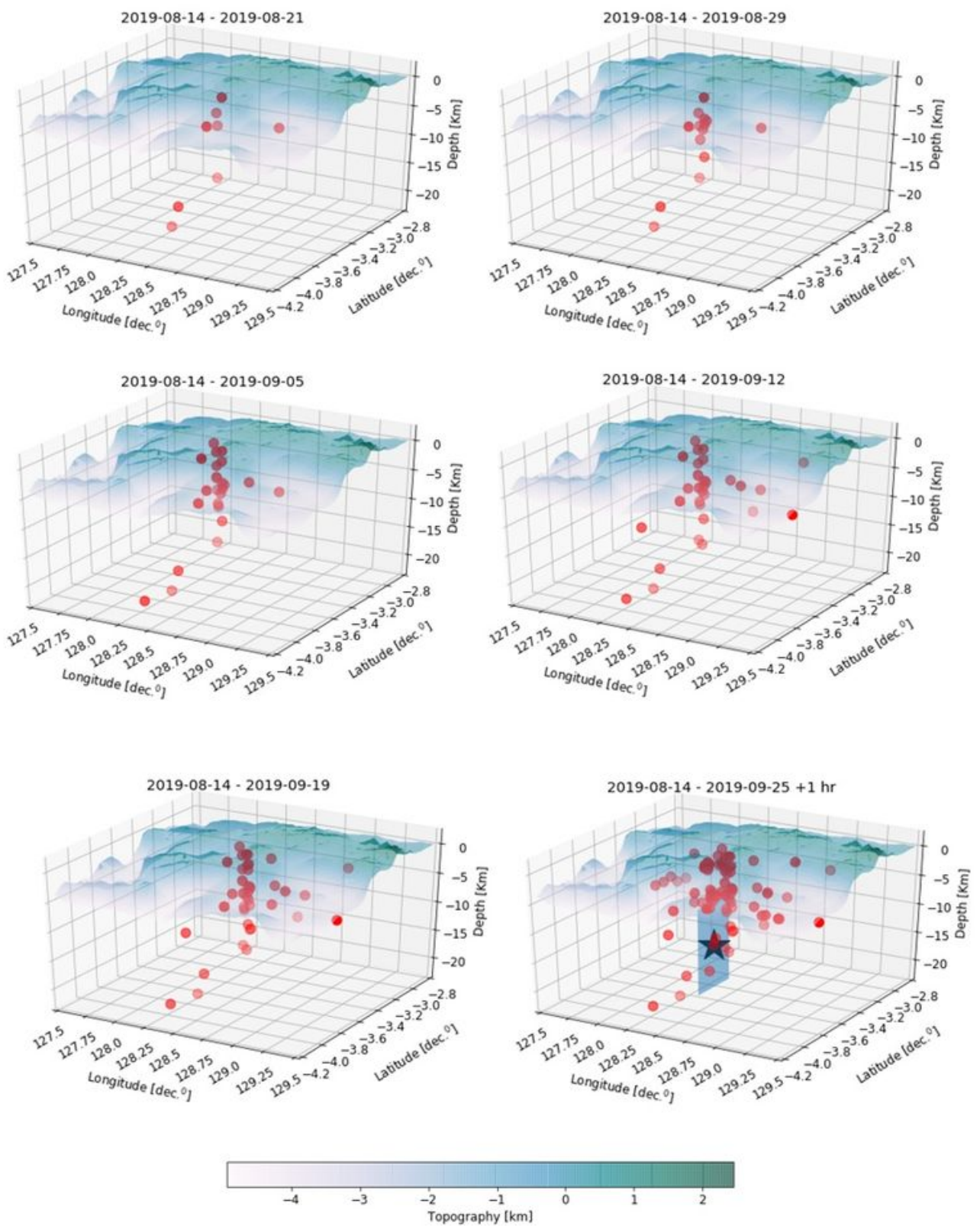

\section{Figure 4}

Seismicity growth episode preceding the Mw 6.6 Ambon earthquake at a selected timeline. The black star depicts the mainshock, red dot indicating seismicity. Blue patches showing fault area estimation, please note that the differences of scaling in longitude-latitude in decimal degree and depth in $\mathrm{km}$. 


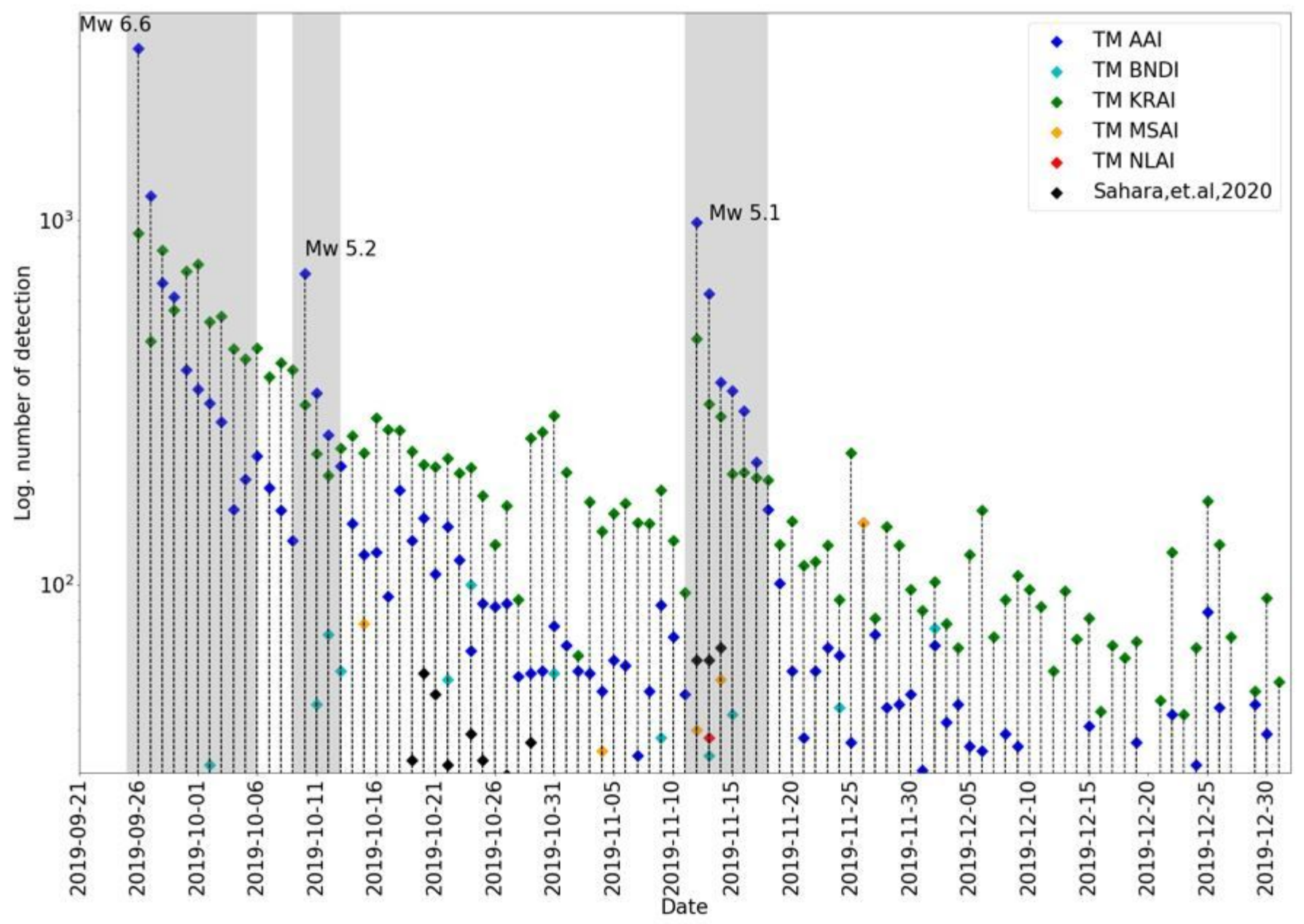

Figure 5

Detection of template matching at each station around the epicentre of Mw 6.6 Ambon earthquake. 


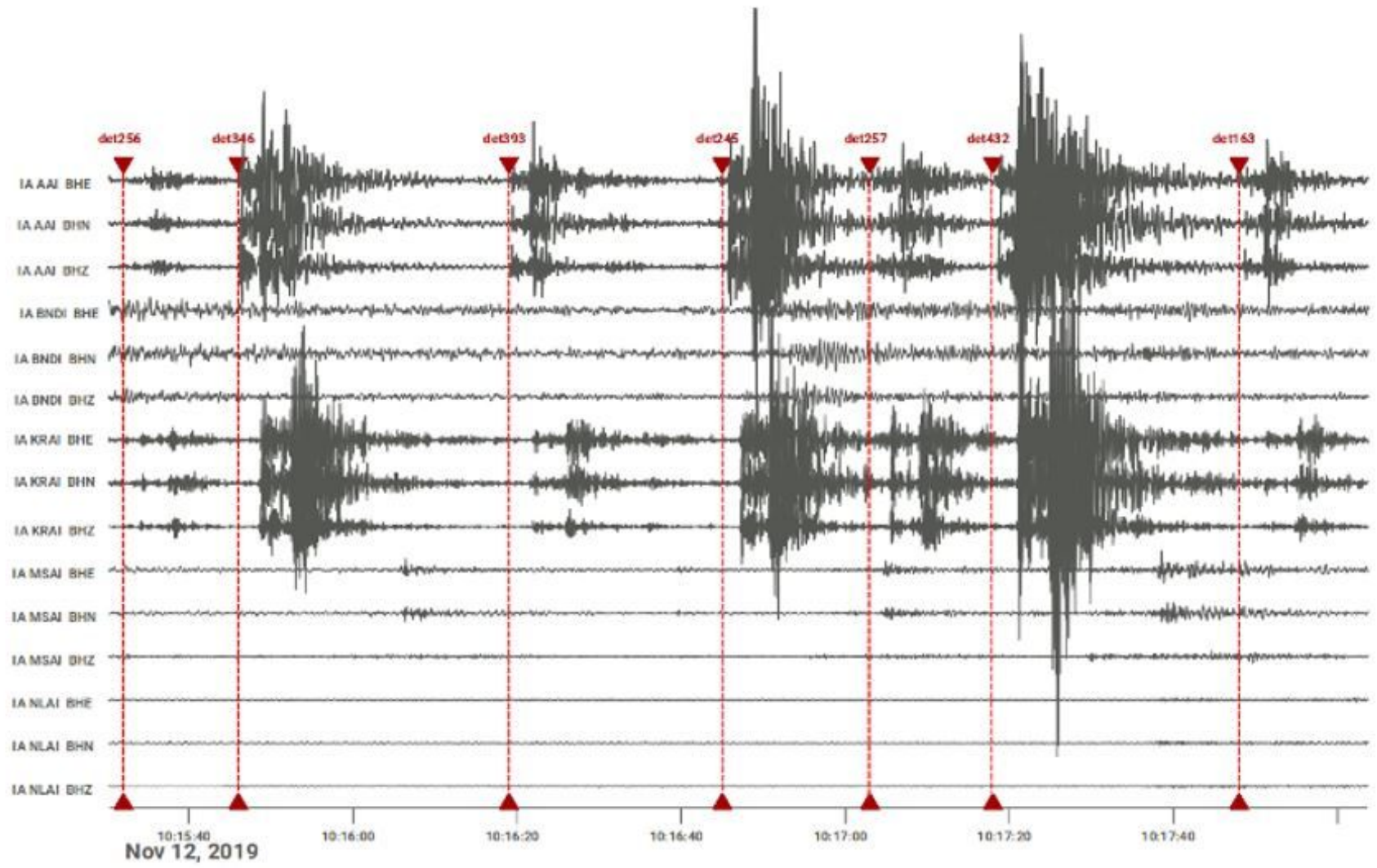

Figure 6

Earthquake sequence on 12 November 2019. Red lines indicate detection time performed by the template matching algorithm. 